\title{
Capitalização da vida nos bancos de células-tronco umbilicais: interrogantes à Psicologia na produção subjetiva
}

\section{The capitalization of life on the umbilical cord blood banking: questions to psychology in the production of subjectivity}

\author{
Capitalización de la vida en los bancos de células madre de \\ cordón umbilical: interrogadores a la Psicología en la \\ producción de la subjetividad
}

\author{
Renata Vilela Rodrigues* \\ Universidade Federal de Mato Grosso - UFMT, Cuiabá, Mato Grosso, Brasil
}

\begin{abstract}
RESUMO
A comercialização das células-tronco encontradas no sangue do cordão umbilical constitui uma das facetas da biopolítica, na qual a vida é comercializada, administrada e governada por uma variedade de empresas em Medicina Regenerativa. Apoiado nos aportes teórico-metodológicos focaultianos e da Teoria Ator-Rede, este trabalho tem como objetivo problematizar as estratégias biopolíticas, na contemporaneidade, as quais impulsionam uma capitalização da vida nos bancos públicos e privados de células-tronco do cordão umbilical, com foco no Brasil. Nesses bancos, partes do corpo tornam-se fonte de capital, as quais se ligam a uma rede heterogênea de aparatos biotecnológicos que mobilizam subjetividades articuladas a políticas de afetividade. As utilizações de biotecnologias direcionadas à manipulação das células-tronco do cordão umbilical viabilizam modos de subjetividades configuradas como empresariais, as quais reivindicam para si o cuidado de sua saúde e a otimização da vitalidade.
\end{abstract}

Palavras-chave: células-tronco, capitalização, biopolítica, subjetividades.

\section{ABSTRACT}

The commercialization of stem cells found in umbilical cord blood is one of the facets of biopolitics in which life is marketed, managed and governed by a variety of Regenerative Medicine companies. Supported by theoretical and methodological Foucaultian and actor-network-theory contributions, this paper aims to discuss contemporary biopolitical strategies, which drive a capitalization market of life in the public and private banks of umbilical cord stem cells focused on Brazil. In these banks, body parts become a source of capital, which attach themselves to a heterogeneous network of biotechnological devices that mobilize subjectivities, articulating political affectivities. The use of biotechnologies aimed at manipulating the umbilical cord stem cells enable subjectivities modes configured as entrepreneurial, which claim for themselves the care of their health and the optimization of vitality.

Keywords: stem cells, capitalization, biopolitics, subjectivities. 


\begin{abstract}
RESUMEN
La comercialización de las células madre que se encuentran en la sangre del cordón umbilical es una de las facetas de la biopolítica, en el que la vida se comercializa, gestionada y gobernada por una variedad de empresas en Medicina Regenerativa. Apoyado en los aportes teóricos y metodológicos focaultianos y la teoría del actor-red, el presente trabajo tiene como objetivo discutir las estrategias de biopolítica, en la época contemporánea, que impulsan una capitalización de mercado de la vida en los bancos públicos y privados de células madre de cordón umbilical, centrándose en Brasil. Estos bancos, las partes del cuerpo se convierten en una fuente de capital, que se unen a una red heterogénea de dispositivos biotecnológicos que con respecto a políticas afecto. El uso de las biotecnologías destinadas a la manipulación de las células madre del cordón umbilical permiten subjetividades que reclaman para sí el cuidado de su salud y la optimización de la vitalidad.
\end{abstract}

Palabras clave: células madre, capitalización, biopolítica, subjetividades.

\title{
I ntrodução
}

As utilizações biotecnológicas direcionadas à manipulação das célulastronco do cordão umbilical parecem se constituir como novas promessas para a cura de algumas patologias existentes e outras que sequer foram identificadas. Segundo Nardi (2007), células-tronco são consideradas as células "mães" do corpo humano, devido à sua capacidade de se proliferar, dando origem, por mitose, a duas células iguais à original ou, quando submetidas a estímulos adequados, a variadas células mais maduras capazes de reconstituir tecidos, células ou alguns órgãos lesionados.

Após descobertas do poder generativo das células-tronco do cordão umbilical, bancos têm ofertado serviços de coleta, criopreservação e armazenamento de tais células. No Brasil, existem dois sistemas de bancos: (1) bancos privados, são aqueles que coletam, realizam testes laboratoriais, processamento, criopreservação, armazenamento e liberação de células-tronco para a família, a qual paga para armazenar o sangue do cordão de seus filhos e, quando do desenvolvimento de alguma patologia, seja da criança cujo cordão foi armazenado, seja de algum familiar mais próximo, pode recorrer às células-tronco armazenadas para terapêuticas e (2) bancos públicos, que ofertam os mesmos serviços que os privados, com a diferença de que as células-tronco do cordão umbilical são coletadas de um ou mais doadores anônimos, processadas, criopreservadas, armazenadas e utilizadas por qualquer pessoa que necessite do transplante. Até o momento da presente pesquisa, existem, segundo dados da Agência de Vigilância Sanitária nacional, 20 bancos privados e 12 bancos públicos de células-tronco do cordão umbilical (Agência de Vigilância Sanitária [Anvisa], 2015). 
A comercialização das células-tronco encontradas no sangue do cordão umbilical constitui uma das facetas da biopolítica, na qual a vida é comercializada, administrada e governada por uma rede sociopolítica de empresas em Medicina Regenerativa, caracterizadas pela regulação e vigilância da vida, em sua dimensão molar e molecular. É válido lembrar que a biopolítica singulariza-se pela entrada dos fenômenos próprios da vida nos cálculos e mecanismos de saber e poder da economia neoliberal (Foucault, 2008).

Alguns fatores contribuíram para a entrada das células-tronco do cordão umbilical na biopolítica contemporânea: primeiro, como vimos apontando, por seu poder generativo, ou seja, sua capacidade em se transformar em outras células ou tecidos do corpo humano, gerando, com isso, vitalidade. Segundo, porque os procedimentos de obtenção das células umbilicais não são tão invasivos ao corpo humano, quando comparados com os de outras células-tronco, como a medula óssea, por exemplo, já que a coleta do sangue do cordão umbilical é realizada no ato do nascimento do bebê, após o corte do cordão umbilical, não sendo identificados ainda danos físicos à mãe ou à criança e não demandando maior tempo de internação para ambos. Além do mais, quando da necessidade do transplante, potencialmente, poupar-se-ia tempo com a procura de um doador compatível, pois, em tese, as células umbilicais devem estar disponíveis em sistemas (semi)automatizados dos bancos, assim que se necessita delas. E, terceiro, em função de sua facilidade de compatibilidade com o receptor, uma vez que as células-tronco encontradas no sangue do cordão umbilical apresentam menor incidência da doença enxerto versus receptor, por incompatibilidade do sistema HLA ${ }^{1}$ (Antígenos Leucócitarios Humanos), principalmente, porque são células mais "imaturas" imunologicamente.

A lógica do mercado econômico em torno das células-tronco do cordão umbilical consiste em medidas precaucionárias contra possíveis doenças futurológicas. Conforme afirma Rose (2011a, 2013), estamos assistindo ao eclodir de uma nova ética somática, na qual as obrigações para com a saúde estão imbuídas de esperança e de ações no presente orientadas para o futuro.

O armazenamento das células-tronco do cordão umbilical e suas aplicações começaram a modificar a importância outorgada às diferentes áreas do conhecimento, incluindo a Psicologia, criando algumas problemáticas sociais que devem ser consideradas (Acero, 2011). Entre os temas que se redefinem, destaquemos: as estratégias políticas e econômicas enredadas na comercialização de partes do corpo e os modos de subjetivações que emergem; os arranjos legislativos os quais regulam a comercialização dos serviços de coleta e armazenamento das células-troncos e as propagandas que impulsionam o aumento dos serviços de coleta e armazenamento nos bancos, principalmente aqueles de caráter privado. 
Vale ressaltar que, por subjetividade, entendemos os "[...] efeitos de composição e recomposição de forças, práticas e relações que se esforçam ou operam para transformar o ser humano em diversas formas de sujeito", constituídas por meio das próprias práticas desse sujeito, bem como das práticas de outros sobre ele. Nessa direção, não se deve entender a subjetivação localizando-a em um universo de sentido ou em um contexto interacional de narrativas, mas, em um complexo de aparatos, práticas, maquinações e composições dentro do qual somos frabricados, e que pressupõe e participa de relações particulares conosco mesmos (Rose, 2011b, p. 236).

Atentando-se às problemáticas biopolíticas presentes na comercialização das células-tronco umbilicais, a presente comunicação de tese tem como objetivo traçar alguns pressupostos trabalhados na dissertação "Capitalização da vida nos bancos de células-tronco do cordão umbilical: Interrogantes à Psicologia na produção de subjetividade", que teve como objetivo problematizar a maneira como questões específicas da vida e da população foram postas no interior de tecnologias de governo que regem a conduta humana e performam subjetivações cada vez mais precaucionárias, temerosas e caracterizadas pelo empresariamento de si.

Mais especificamente, examinou as estratégias biopolíticas, na contemporaneidade, que impulsionam uma capitalização da vida nos bancos públicos e privados brasileiros que coletam, criopreservam e armazenam o sangue do cordão umbilical. Analisou alguns dos arranjos legislativos que regulam a comercialização dos serviços de coleta e armazenamento de células-tronco do cordão umbilical nacional. Em acréscimo, investigou a relação psicossocial tecida nas interações online entre pais (e seus filhos) e os bancos de célulastronco do cordão umbilical, em homepages de empresas brasileiras.

\section{Estratégias biopolíticas na comercialização de células-tronco umbilicais}

As descobertas em genética que possibilitaram a manipulação e comercialização das células-troncos encontradas no sangue do cordão umbilical, bem como os desenvolvimentos biotecnológicos das últimas décadas invadiram as problematizações científicas, em diversas áreas do conhecimento, além de povoar o imaginário e o cotidiano das pessoas. É principalmente por essa disseminação que tais descobertas também são alvos de intensas polêmicas, controvérsias e reflexões sobre suas dimensões éticas, políticas e econômicas (Arendt $\&$ Costa, 2005).

O debate em torno da disponibilidade e dos usos terapêuticos das células-tronco do cordão umbilical está sendo constituído por uma rede sociotécnica de pesquisas, que se iniciou no começo do século 
XX. Nessa rede, diversos saberes foram acionados: Psicologia, Biologia, Genética, Biotecnologia, Engenharia, Biomedicina, Medicina Regenerativa, destacando-se também o Direito, na medida em que atua tipificando o que é lícito e ilícito nas manipulações genéticas e biotecnológicas; a Economia, quando instituições bancárias públicas e privadas e órgãos de fomento investem nas pesquisas genéticas e biotecnológicas e, não poderíamos deixar de mencionar, a Política que, ao mesmo tempo em que possibilita estratégias governamentais de intervenção na comercialização das partes genéticas e no patenteamento das descobertas, está articulada a todos os outros saberes, propiciando intervenções políticas e econômicas no sentido de otimização da própria vida. Essas diferentes práticas e áreas do saber formulam igualmente certa ideia, um modelo de veridicção sobre o que somos e o que nos tornamos (Foucault, 2012) a partir da manipulação dos nossos corpos e da genética que carregamos.

A Psicologia, em particular, tem cada vez mais se interessado pelos trabalhos em biotecnologias e genética, bem como sobre os modos de subjetivação que se instauram a partir do desenvolvimento desses dois campos de intervenção. Com as novas biotecnologias e as demandas em saúde, através de testes preditivos genéticos, emergem indivíduos preocupados e temerosos que vivenciam sua saúde em termos de probabilidades do desenvolvimento de alguma doença no futuro e que, paulatinamente, demanda precisão desses testes. Assim, as maneiras como nos subjetivamos estão cada vez mais atravessadas por biotecnologias, de modo que aspectos que seriam tradicionalmente endereçados a outras áreas de saber passam também a trazer questões que interessam à Psicologia, colocando indagações aos modos de subjetivação que pautam a constituição do sujeito psicológico, no contemporâneo.

As biotecnologias estão inseridas na problemática da constituição do eu, quando trazem determinados domínios de nós mesmos, a partir do momento em que as práticas de cuidado com o corpo se tornam mais constantes e intensas com a abertura do código genético. Nessa direção, os interesses da Psicologia pela inovação biotecnológica podem ser visualizados tanto na problematização realizada pelo campo científico sobre os modos de subjetivações que emergem do acoplamento entre biotécnicas e corpo quanto em seu campo de atuação profissional, por meio de psicoterapias de aconselhamento genético. Chamamos a atenção, nesse sentido, para as formas de subjetivações as quais emergem na comercialização das célulastronco umbilicais, caracterizadas, sobretudo pelo empresariamento de si.

Alguns dos saberes e órgãos que atuam na rede de comercialização e manipulação das células-tronco estão em localidades distintas, a exemplo das atuações e problematizações psicológicas, de centros de pesquisas internacionais e os bancos com sedes em territórios 
nacionais que dialogam sobre os desenvolvimentos em genético, ou até mesmo pais de um estado brasileiro localizado no Centro-Oeste que contrata os serviços de um banco no Sudeste. A junção de agentes tão distintos para alcançar um interesse comum pode ser explorada pela noção de tradução, proposta por Callon e Latour (1981).

Tradução refere-se a todas as negociações que um ator ou força assume, ou faz com que seja concebida para si autoridade para falar ou agir em nome de outro ator ou força. Quando um ator fala, ele está traduzindo outro ator do qual ele se torna porta-voz, já que os interesses de ambos são os mesmos. É por meio desse processo de tradução que agentes diferentes (empresas nacionais e transnacionais; mães, pais e crianças; indústrias biotecnológicas, bancos de células-tronco, instituições de fomento) podem ser assimilados em uma rede, a ponto de virem a interpretar seus objetivos destinos como sendo, de certa forma, inextricáveis. Quando uma ação, um enunciado ou um objeto passa pelo processo de tradução, ele nunca sai da mesma forma que entrou, pois há um deslocamento (um desvio) do seu curso. Nessa direção, quando um ator passa pela tradução, mesmo que suas propriedades internas permaneçam as mesmas, algo no curso de sua ação foi modificado (Latour, 1986, 2012).

Para discorrer sobre a comercialização das células umbilicais por bancos públicos e privados brasileiros optamos por utilizar como aporte teórico-metodológico as concepções da Teoria Ator-Rede e os estudos foucaultianos sobre biopolítica. Juntas, essas duas correntes de pensamento nos possibilitaram uma visão desnaturalizada dos saberes, levando a repensar a construção de algumas estratégias de visibilização da política, na produção do conhecimento científico, e suas teorias abrem espaço para pensarmos os modos de subjetivações que são forjados no acoplamento entre orgânico e biotecnologias de células-tronco.

$\mathrm{Na}$ biopolítica em torno da comercialização das células-tronco do cordão umbilical, interesses individuais em melhorar a saúde coincidem com vários interesses coletivos, os quais buscam gerar lucros por meio da comercialização de tecnologias biomédicas de aperfeiçoamento genético. Segundo Rose (2013), tecnologias biomédicas referem-se a ajuntamentos de instrumentos, matérias, técnicas e pessoas que possibilitam agir no presente sobre a conduta das pessoas individual e coletivamente, objetivando a intervenção futura do corpo e com o intuito de gerar lucros às empresas biotecnológicas.

Foucault (2008), em o Nascimento da Biopolítica, já apontava que os desenvolvimentos em genética constituíam um capital humano genético, fonte de renda humana direcionada para o futuro: 
De fato, a genética atual mostra muito bem que um número de elementos muito mais considerável do que se pode imaginar até hoje [é] condicionado pelo equipamento genético que recebemos dos nossos ascendentes. Ela possibilita, em particular, estabelecer para um indivíduo dado, qualquer que seja ele, as probabilidades de contrair este ou aquele tipo de doença, numa idade dada, num período dado da vida ou de uma maneira totalmente banal num momento qualquer da vida. Em outras palavras, um dos interesses atuais da aplicação da genética às populações humanas é possibilitar reconhecer os indivíduos de risco e o tipo de risco que os indivíduos correm ao longo da sua existência. (Foucault, 2008, p. 313).

As células-tronco do cordão umbilical entram no cálculo biopolítico, porque promovem a intersecção de interesses individuais e coletivos, além de favorecer a discussão sobre a relação entre vida e poder. Aqui vale a pena frisar que a comercialização das células-tronco é tratada como questão da biopolítica não somente porque elas têm a ver com genética e, consequentemente, com a vida, mas também porque as inovações biotecnológicas aplicadas às células umbilicais constituem uma forma de articulação entre política e vida e os complexos procedimentos jurídico-políticos. Como bem indica Rodriguéz (2012), manipular os caracteres genéticos humanos concerne a uma materialização de atividades que podem ser reguladas e formam parte de um corpus político-normativo do controle social.

Os assuntos referentes às terapêuticas com células-tronco e aos gastos com seu emprego chamam cada vez mais a atenção do Estado brasileiro, o qual emprega estratégias de regulação visando à prevenção de doenças e, consequentemente, ao aumento de vida útil das pessoas, pelo armazenamento das células umbilicais. O que pode ser visualizado com a aprovação pela Comissão da Educação, Cultura e Esporte do Senado brasileiro, em 2013, do dia Nacional da Doação do Cordão Umbilical ( 8 de outubro), com o intuito de aumentar o contingente de células-tronco disponíveis no país e reduzir os custos com transplantes, tendo em vista o custo baixo do uso da terapêutica com células do cordão umbilical. Com o Dia Nacional da Doação do Cordão Umbilical, a intenção é que informações sobre esse tipo de terapêutica atinjam cada vez mais um número maior de mães.

Neste sentido, as células-tronco do cordão tornam-se assuntos biopolíticos, de um lado, por moldar determinadas características subjetivas, com discursos traçados por condições biológicas de identificação e terminologias assentadas sobre determinados estilos de vida, produzindo modos de subjetividades empreendedoras de si, e, de outro, graças ao seu potencial de gerar vitalidade e sua entrada nos cálculos e mecanismos de poder. 
Waldby (2002) aponta que os interesses médico, político e econômico em células-tronco surgem na interseção de dois problemas biopolíticos. O primeiro relaciona-se ao declínio da mortalidade e, consequentemente, ao aparecimento de mais doenças crônicas e degenerativas (doença vascular cerebral, de Parkison, de Alzheimer, doenças cardíacas, entre outras). O segundo concerne às problemáticas enfrentadas na prática de transplante de órgãos, como insuficiência de órgãos e/ou rejeição imunológica. Em acréscimo, vemos ainda que a escassez de doadores de medula óssea, associada à incompatibilidade dos doadores com os receptores, tem também impulsionado os serviços de células-tronco do cordão umbilical.

Nas tramas biopolíticas que impulsionam a comercialização dessas células, no Brasil, o discurso proeminente consiste em um "sonho", no qual os tratamentos atualmente disponíveis, como farmacologia, transplantes de órgãos e de medula óssea, poderão ser complementados por terapêuticas com as células-tronco do cordão umbilical, tornando o país, com toda sua diversidade étnica, autossuficiente no tratamento de doenças hematológicas cancerígenas e não cancerígenas.

Neste processo de regulação biopolítica das células-tronco umbilicais, os discursos e a caracterização ontológica do cordão umbilical têm mudado, de modo que, na atualidade, ele não só garante uma vitalidade intrauterina, como também extrauterina, visto que o cordão que naturalmente alimenta a criança por nove meses poderá salvá-la, quando do desenvolvimento de alguma patologia no futuro, ao ser modificado e comercializado pelas biotecnologias. A comercialização das células-tronco umbilicais se desenvolve a partir de uma articulação entre capital genético e diversos agentes: negociações comerciais, estruturas orgânicas corporais, estratégias de mercado, doutrinas médicas, economias transnacionais, sistema de trabalho das indústrias científicas, de medo e de esperanças de pacientes consumidores, a família, as empresas privadas e agenciamentos públicos, cientistas nacionais e internacionais que pesquisam as possibilidades de uso dessas células, grupos de pacientes que definem sua cidadania como direito às terapêuticas com células umbilicais. Em alguns bancos, inclusive, visualizamos a extensão de suas atividades para pesquisas com células-tronco e armazenamento de outros tecidos humanos, arregimentando, para redes, atores como universidades federais ou centros privados de pesquisas, serviços de armazenamento de células-tronco provenientes da polpa dentária, bancos de sêmens.

Problematizar a comercialização do cordão umbilical, em sua dimensão biopolítica, faz considerar as relações entre Estado, populações, conhecimento científico e práticas sociais que estão envolvidas na coleta e armazenamento das células-tronco. A biopolítica, na medida em que permite visualizar as complexidades 
dos campos empíricos, alerta-nos para as tramas em que a vida e o poder podem ser enredados.

Política e Ciência se cruzam com diferentes modelos regionais de saúde, e diversos grupos sociais têm sido mobilizados a apoiar e apostar nos desenvolvimentos biomédicos e biotecnológicos. Tal mobilização tem um lugar cada vez mais no contexto de um mercado globalizado, onde o conhecimento e a competição para o controle futuro da economia geram formas de biopolíticas que sucumbem às exigências da competição mercadológica global e, ao mesmo tempo, estão susceptíveis às regulações políticas nacionais (Salter \& Waldby, 2011).

\section{Biocapitalização nos bancos privados e públicos de células- tronco}

A análise do circuito biopolítico de comercialização das células-tronco do cordão umbilical, nos bancos brasileiros, revelam que, a forma de comercialização das células-tronco do cordão umbilical é complexa e fornece um mapa importante dos interesses comerciais, das restrições e confusões regulamentares, da oposição pública e privada dos usos terapêuticos e das relações de poder que as envolvem (Waldby, 2006).

Desde 2003, a Agência de Vigilância Sanitária (Anvisa) regula as atividades dos bancos de células-tronco do cordão umbilical brasileiros, que podem ser visualizadas em cinco relatórios publicados em 2010, 2011, 2013, 2014 e 2015 os quais apresentam informações sobre os dados de produção dos bancos. Nesses relatórios, verifica-se um intenso investimento das famílias em bancos privados. Num intervalo de onze anos, de 22 células-tronco autólogas armazenadas, em 2003, o país passa a possuir 105.074 células armazenadas, em 2014 (Anvisa, 2010, 2011, 2015). Das unidades armazenadas nos bancos privados brasileiros, até 2013, apenas onze foram utilizadas para transplantes, sendo quatro para uso autólogo e sete para uso aparentado (Anvisa, 2013). O relatório de produção referente ao ano de 2014 mostra que nenhuma célula foi utilizada em transplante autólogo e uma unidade foi fornecida para uso aparentado (Anvisa, 2015).

Para o armazenamento das células-tronco em bancos privados, alguns critérios devem ser obedecidos, como quantidade mínima de 500 milhões de células e estar livre de contaminação bacteriana e fúngica. Durante o período em que decorreu para a realização da pesquisa do trabalho dissertativo aqui apresentado, o custo para a coleta e armazenamento do sangue do cordão umbilical por empresas privadas brasileiras variam entre $R \$ 3.000$ e $R \$ 5.000$, com uma taxa anual de manutenção entre $\mathrm{R} \$ 350$ a $\mathrm{R} \$ 500$. 
A coleta e o armazenamento do cordão umbilical em bancos privados reforçam "[...] a colocação da infância como um mercado lucrativo e promissor para os que desejam realizar empreendimentos da vida", na biopolítica contemporânea (Galindo, Lemos \& Rodrigues, 2014, p. 258). Ao pagar para armazenar o material biológico do seu filho num banco privado, os pais estão realizando um investimento que pode, num futuro, salvar sua vida, mesmo que as chances de utilização sejam ínfimas. A capitalização da vida, nessas empresas, é arregimentada através da construção de discursos esperançosos e expectativas. A própria vida faz parte de uma relação lucrativa entre os pais e a saúde privativa, na qual o sangue do cordão umbilical é um capital de risco biológico (Mitchel \& Waldby, 2009, Waldby, 2002).

Os bancos privados enfatizam um valor que é, ao mesmo tempo, prudencial e especulativo. Em seu aspecto prudencial, coletar e armazenar as células umbilicais assemelham-se aos princípios neoliberais dos seguros de saúde privada, os quais oferecem serviços de gestão de risco caracterizados como uma proteção contra as incertezas do futuro. No seu aspecto especulativo, prometem a cura de doenças de origem hematológica e uma otimização do tempo vital, por meio de promessas quanto a prováveis descobertas em pesquisas com células-tronco adultas (Waldby, 2002, Waldby \& Mitchel, 2006).

No Brasil, os bancos públicos de células-tronco do cordão umbilical são unidades mantidas financeiramente pelo setor público e constituintes da Rede BrasilCord, a qual tem por objetivo coordenar e gerenciar a expansão da rede pública, os recursos financeiros e reunir os bancos públicos. Essa rede foi criada, em 2004, por meio da Portaria Ministerial no 2381 de 29/10/2004 e é coordenada pelo diretor do Centro de Transplante de Medula Óssea, do Instituo Nacional do Câncer (INCA) (Anvisa, 2013).

As atividades dos bancos públicos são mencionadas a partir da edição de 2013 dos relatórios da Anvisa, com restrições, pois cinco unidades não enviaram seus dados de produção no ano de 2011 e três em 2012 (Anvisa, 2013). O último relatório emitido pela Anvisa, intitulado de "Relatório de Avaliação dos Dados de Produção dos Bancos de Sangue de Cordão Umbilical e Placentário", em 2014, evidencia que existem apenas 2.414 células-tronco do cordão umbilical armazenadas nos bancos públicos. Das células armazenadas, cinco foram utilizadas para transplantes, 25 foram disponibilizadas para pesquisa e 75 para o ensino e validação de processos (Anvisa, 2015). Dessa forma, mesmo que o objetivo principal da rede pública seja possuir o maior número de célulastronco possíveis (Santoro, 2009), sem um número expressivo de doações, as terapêuticas com essas células não podem se tornar um procedimento de rotina. 
No relatório de produção do ano de 2013, percebe-se que nos anos de 2011 e 2012 foram armazenadas na Rede BrasilCord 14 e 43 unidades para utilização alogênica aparentada (Anvisa, 2010, 2013). Em 2014, foram armazenadas 33 unidades para esta finalidade, destas três foram fornecidas para transplante (Anvisa, 2015). Esse tipo de serviço é realizado mediante indicação médica, e o cordão umbilical da criança passa a ser destinado para uso exclusivo de algum membro da família que esteja necessitando do transplante. Nesses casos, os serviços são oferecidos gratuitamente e as células umbilicais são de uso exclusivo da pessoa indicada para a terapêutica. Nesta direção, os discursos de patrimonialização pública que rondam os serviços públicos brasileiros com células-tronco do cordão umbilical, em que teoricamente, toda a população teria acesso aos usos dessa técnica, ficam no plano do ideário.

Nos bancos públicos, percebe-se que a doação do cordão umbilical está ligada a discursos político-sociais em torno de valores comunitários como altruísmo, generosidade e solidariedade social. $\mathrm{O}$ ato de doar leva a considerar os bancos públicos e as redes de regulação que os conectam como bens sociais (Sullivan, 2008; O'Connor, Samuel, Jordens \& Kerridge, 2012). Apesar de carregarem a gratuidade em seus discursos, os bancos públicos, assim como os privados, mobilizam intensos fluxos de capital. No Brasil, cada unidade pública tem custado para o governo federal cerca de $R \$ 3,5$ milhões quando da sua criação. Em 2008, foram investidos $\mathrm{R} \$ 31,5$ milhões do Banco Nacional de Desenvolvimento Econômico e Social (BNDS) na rede BrasilCord para a ampliação dos bancos, estimandose que mais unidades sejam instaladas. Investimentos consideravelmente altos, se comparados com os números de célulastronco armazenadas e os de transplantes realizados no país com tais células.

Para Waldby e Mitchell (2006), o valor clínico dos bancos públicos de células-tronco reside em sua redistribuição como um presente na economia de mercado, que se concentra sobre a necessidade de se acumular o quanto possível de material biológico. Enquanto, no armazenamento para uso individual das células umbilicais, ou seja, autólogo, a economia gira em torno da capacidade regenerativa das células para uso próprio, nos bancos públicos, o capital é retirado como uma forma de presente do doador para o receptor, visando à acumulação máxima de células.

Duarte, Miyadahira e Zugaib (2009), ao discorrerem sobre as controvérsias que envolvem o armazenamento público/privado das células-tronco umbilicais, mostram que, apesar de as células-tronco provenientes do cordão umbilical serem indicadas para o tratamento de "doenças malignas aplásticas da medula óssea, doenças metabólicas hereditárias e imunológicas e após uma mielo ablação" (p. 4), as indicações dos usos terapêuticos em doenças degenerativas 
de tais células são especulativas e prematuras. No que se refere ao uso autólogo, os autores indicam ainda que "a chance de o doador desenvolver doença passível de tratamento por essas células, até a idade de 20 anos, é de 1: 10.000 a 1:200.000" (p. 4).

$\mathrm{Na}$ lógica neoliberal de governar os corpos e as condutas, as célulastronco do cordão umbilical acabam se tornando mercadorias, matérias-primas. Mesmo os bancos públicos que são construídos com base em ideários de altruísmo, tais discursos tornam-se secundários diante da obtenção de recursos e interesses econômicos estatais (Brown, Machin \& Mcleod, 2011). Dessa forma, as estratégias biopolíticas de bancos que comercializam as células-tronco do cordão umbilical sinalizam para uma dinâmica de capitalização da vida, na qual serviços biotecnológicos visam a assegurar as pessoas diante de futuros incertos. E, ao mesmo tempo, alimentam precariedades sociais, políticas e econômicas e elevam as incertezas, ansiedades e medos.

\section{Considerações finais}

Apesar dos denominados progressos científicos, a felicidade prometida ainda continua sem garantias de ser alcançada, nas terapêuticas com células umbilicais. Cardoso e Castiel (2003), na conclusão de um trabalho sobre genética e saúde coletiva, sublinham uma preocupação em torno dos esforços das biotecnologias em mapear e sequenciar os "problemas genéticos" não sucumbirem a um determinismo e a um endeusamento, fetichização e/ou dogmatização dos riscos genéticos. Mais de dez anos depois, vemos que tais preocupações ainda vigoram.

Basta abrimos um guia de notícias da internet sobre células-tronco, para vermos que, em meio a diversas mensagens sobre os maravilhosos progressos científicos, há recorrentemente a menção a palavras como "provavelmente", "futuro", "em poucos anos". Além do mais, como as terapêuticas com as células umbilicais ainda são recentes, não se sabe quais os efeitos em longo prazo nos corpos, especialmente aqueles advindos do próprio material biológico, como ocorrem nos transplantes autólogos, ou seja, quando se utiliza o mesmo material genético em terapêuticas genéticas. A capitalização da vida nos bancos de células-tronco do cordão umbilical constitui um investimento que pode ou não vir a se concretizar. Essa capitalização é expressa em números e/ou retornos de investimento, pois o que está em jogo não são retornos seguros e quantificáveis em números, mas promessas e expectativas as quais vinculam o presente e 0 futuro numa rede de investimentos financeiros e afetivos (Brown \& Kraft, 2006). 
Além do mais, as intervenções tecnológicas em Medicina Regenerativa não suspendem, nem melhoram as relações sociais de exclusão e inclusão, nas quais estamos imersos historicamente, por meio de eixos de classes e divisões socioeconômicas (Braidotti, 2007). O investimento na saúde - do qual os bancos são apenas uma das ramificações - como um patrimônio empreendido pelas camadas médias brasileiras e o mercado criado em seu em torno abrem um campo de interrogações sobre processos de subjetivação que importam, porque assinalam que cada novo investimento privado é igualmente uma resignação diante de desigualdades nas quais não se questiona uma possível distribuição equitativa do capital biológico em questão, nem mesmo a possibilidade de sua não capitalização. As imagens de divulgação presentes nas páginas eletrônicas dos bancos privados nos fazem indagar sobre o imperativo da segurança patrimonial das células dos corpos, essa nova obrigação moral para aqueles que podem contratar os serviços ofertados.

Nos bancos brasileiros públicos e privados de células-tronco do cordão umbilical, discursos esperançosos quanto a um futuro imune de patologias e a expectativa do aumento da longevidade num futuro próximo configuram os motivos que impulsionam e movimentam grande parte de suas atividades lucrativos. Nesses bancos, vemos estratégias voltadas para a comercialização da vida reguladas, principalmente, por políticas de afetividade. A vida afetiva das pessoas é alvo e condição para novas formas contemporâneas de governamentalidade (Anderson, 2012), nas quais relações de afeto e amor são ferramentas de poder e controle dos corpos e arregimentam a capitalização da vida.

Para finalizar, ressaltamos que essas novas formas de problemáticas biopolíticas que estão emergindo, durante o século XXI, como a comercialização das células-tronco do cordão umbilical, se relacionam e se dão com outros problemas biopolíticos direcionados às políticas públicas, como, por exemplo, as zonas de espera dos aeroportos, a escassez de transportes públicos, as negligências nos hospitais e escola, dentre muitos outros tão comuns em países denominados "em desenvolvimento" ou "emergentes", como o Brasil.

Algumas dessas problemáticas interferem diretamente na circulação das células-tronco umbilicais: imaginemos, por exemplo, que pais residentes num Estado do Centro-Oeste brasileiro contratem os serviços de um banco que possui sua matriz em outro Estado, localizado no Sudeste, necessitando de transporte aéreo para que as células possam ser criopreservadas e armazenadas no laboratório da empresa, o que demanda aeroportos e sistemas aéreos com um mínimo de qualidade. Dessa forma, devemos ater-nos às novas formas sutis de problematizações biopolíticas, na medida em que articulam as precárias condições nacionais ou regionais ao intenso investimento transnacional. 
As precariedades em Políticas Públicas merecem nossa atenção, visto que mesmo, sendo convocados a negociar e concorrer com os grandes centros de comércio de biotecnologias, como China, Índia, Estados Unidos e alguns países europeus, na economia liberal atual, ainda enfrentamos graves problemas econômicos e sociais que há bastante tempo deixaram de ser realidade em outras localidades.

Destaquemos, ainda, que os estudos empreendidos, na dissertação apresentada aqui, abrem caminho para posteriores discussões, incluindo, por exemplo, uma exploração das formas e estados de racismos da comercialização das células-tronco do cordão umbilical, a complexa rede de regulação nacional das atividades dos bancos privados e públicos e uma análise criteriosa da divulgação científica em biotecnologias, de maneira a sublinhar como os discursos biomédicos estão sendo incorporados nas práticas cotidianas de saúde das mulheres grávidas.

\section{Referências}

Acero, L. (2011). Pesquisas e terapias com células-tronco: governança, visões sociais e o debate no Brasil. Rio de Janeiro: e-papers.

Agência de Vigilância Sanitária [Anvisa]. (2010). Bancos de sangue de cordão umbilical e placentário para uso autólogo: relatório de produção 2003/2009. Recuperado em 25 de Junho, 2016, de http://portal.anvisa.gov.br/documents/33840/329805/relatorio \% 252BBSCUPA. pdf/6f5b164c-9131-421d-97e7-507502a74e8d

Agência de Vigilância Sanitária [Anivisa]. (2011). Bancos de Sangue de Cordão Umbilical e Placentário para Uso Autólogo (BSCUPA): relatório de produção 2003 - 2010. Recuperado em 25 de Junho, 2016, de http://portal.anvisa.gov.br/wps/wcm/connect/e287d20049006e 28a4a7bc466b74119d/BSCUPA+2010. pdf?MOD=AJ PERES

Agência de Vigilância Sanitária [Anvisa]. (2013). Relatório de Avaliação dos dados de produção dos bancos de sangue do cordão umbilical e placentário. Recuperado em 25 de Junho, 2016, de

http://portal.anvisa.gov. br/documents/33840/2818460/Relat\% C3\% B3rio+de+Avalia\% C3\% A7\% C3\% A3o+dos+Dados+de+Pro du\% C3\% A $7 \%$ C3\% A3o+dos+Bancos+de+Sangue+de+Cord\% C $3 \%$ A3o+Umbilical+e+Placent\% C3\% Alrio++2011+e+2012/97129577-8444-48ea-99ad-4731a42ae23e

Agência de Vigilância Sanitária [Anvisa]. (2014). Relatório de Avaliação dos Dados de Produção dos Bancos de Sangue de Cordão Umbilical e Placentário: Ano 2013 incluindo o retrospecto de dez anos de armazenamento privado no Brasil. 
Recuperado em 31 de Julho, 2016, de http://portal.anvisa.gov. br/documents/33840/2818460/Relat\% C3\% B3rio+de+Avalia\% C3\% A7\% C3\% A3o+dos+Dados+de+Pro du\% C3\% A7\% C3\% A3o+dos+Bancos+de+Sangue+de+Cord\% C $3 \%$ A3o+Umbilical+e+Placent\% C3\% A1rio+- +2013/0084f1f5c664-4bd2-b72c-02b0a335e3e0

Agência de Vigilância Sanitária [Anvisa]. (2015). Relatório de Avaliação dos Dados de Produção dos Bancos de Sangue de Cordão Umbilical e Placentário. Recuperado em 31 de Julho, 2016 , de http: //portal. anvisa.gov. br/documents/219201/219401/Relat\% 25C3\% 25B3rio\% 2Bde\% 2BAvalia\% 25C3\% 25A7\% 25C3\% 25A30 $\%$ 2Bdos\% 2BDados\% 2Bde\% 2BProdu\% 25C3\% 25A7\% 25C3\% 25 A30\% 2Bdos $\%$ 2BBancos $\%$ 2Bde\% 2BSangue $\%$ 2Bde\% 2BCord\% 2 5C3\% 25A30\% 2BUmbilical\% 2Be\% 2BPlacent\% 25C3\% 25A1rio\% 2B2014.pdf/d86b7c03-d5b0-47d3-95b2-7eb759a8fa9c

Anderson, B. (2012). Affect and biopower: towards a politics of life. Transactions of the Institute of British Geographers, 37, 28-43.

Arendt, R. J. J., \& Costa, C. A. M. (2005). O corpo como fe(i)tiche Possíveis contribuições do pensamento de Bruno Latour a Psicologia. Mnemosine, 1(2), 47-74.

Braidotti, R. (2007). Bio-power and Necro-politics. Springerin, Hefte fur Gegenwartskunst, 13(2), 18-23.

Brown, N., \& Kraft, A. (2006). Blood Ties: banking the Stem Cell Promise. Technology Analysis \& Strategic Management, 18(3/4), 313-327.

Brown, N., Machin, L., \& Mcleod, D. (2011). Immunitary bioeconomy: The economisation of life in the international cord blood Market. Social Science \& Medicine, 72, 1115-1122.

Callon, M., \& Latour, B. (1981). Unscrewing the big Leviathan: how actors macro-structure reality and how sociologists help them to do so. In K. Knorr-Cetina \& A. V. Cicourel (Eds.), Advances in social theory and methodology: toward an integration of microand macro-sociologies (pp. 277-303). Boston: Routledge $\&$ Kegan.

Cardoso, M. H. C. A., \& Castiel, L. D. (2003). Saúde coletiva, nova genética e a eugenia de mercado. Cad. Saúde Pública, 19(2), 653-662.

Duarte, S., Miyadahira, S., \& Zugaib, M. (2009). Armazenamento de sangue de cordão umbilical e placenta: público, privado ou ambos? Revista da Associação Médica Brasileira, 55(1), 4-5.

Foucault, M. (2008). O Nascimento da Biopolítica. São Paulo: Martins Fontes.

Foucault, M, (2012). Ética, Sexualidade, Política. Coleção Ditos e Escritos V. Rio de Janeiro: Forense Universitária. 
Galindo, D., Lemos, F. C., \& Rodrigues, R. V. (2014). A vida como biocapital - futuros biológicos, uma aposta dos bancos privados de células-tronco de cordão umbilical no Brasil. Athenea Digital, $14(2), 255-274$.

Latour, B. (1986). Visualization and cognition: Drawing things together. Knowledge and Society, 6, 1-40.

Latour, B. (2012). Cogitamus: seis cartas sobre las humanidades científicas. Buenos Aires: Paidós.

Mitchell, R., \& Waldby, C. (2009). National Biobanks: Clinical Labor, Risk Production, and the Creation of Biovalue. Science Technology Human Values, 35(3), 30-355.

Nardi, N. B. (2007). Células-tronco: fatos, ficção e futuro. Genética na Escola, 2(2), 25-29.

O'Connor, M., Samuel, G., Jordens, C. F. C., \& Kerridge, I. H. (2012). Umbilical cord blood banking: Beyond the public-private divide. J ournal of law and medicine, 19(3), 512-516.

Rodriguéz, I. S. (2012). La movilidad de los objetos tecnocientíficos: un ejemplo de biopolítica a través de las patentes. Política y Sociedad, 49(3), 549-570.

Rose, N. (2011a). Biopolítica molecular, ética somática e o espírito do biocapital. In L. H. S. Santos \& P. R. C. Ribeiro (Orgs.). Corpo, gênero e sexualidade: instâncias e práticas de produção nas políticas da própria vida (pp. 13-32). Rio Grande: FURG.

Rose, N. (2011b). Inventando nossos selfs: Psicologia, poder e subjetividade. Petrópolis, RJ : Vozes.

Rose, N. (2013). A política da própria vida: biomedicina, poder e subjetividade no século XXI. São Paulo: Paulus.

Salter, B., \& Wadby, C. (2011). Biopolitics in China: An Introduction. East Asian Science, Technology and Society: An International Journal, 5, 287-290.

Santoro, P. (2009). From (public?) waste to (private?) value. The regulation of private cord blood banking in Spain. Science Studies, 22(1), 3-23.

Sullivan, M. J. (2008). Banking on cord blood stem cells. Perspectives, 8, 554-563.

Waldby, C. (2002). Biomedicine, tissue transfer and Intercorporeality. Feminist Theory, 3(3), 239-254.

Waldby, C. (2006). Oöcyte markets: global tissue economies and women's reproductive work in embryonic stem cell research. New Genetics and Society, University of Sydney NSW.

Waldby, C., \& Mitchell, R. (2006). Tissue Economomies: blood, organs, and cell lines in late capitalismo. Durham and London: Duke University Press. 


\section{Endereço para correspondência}

\section{Renata Vilela Rodrigues}

Universidade Federal de Mato Grosso - UFMT

Instituto de Linguagens / ECCO

Av. Fernando Corrêa da Costa, 2367 sl 44/IL, Boa Esperança, CEP 78060-900, Cuiabá - MT, Brasil

Endereço Eletrônico: renata_vilelarvr@hotmail.com

Recebido em: 05/05/2016

Reformulado em: 14/02/2017

Aceito em: 14/03/2017

\section{Notas}

* Mestra em Estudos de Cultura Contemporânea pelo Programa de Pós-graduação em Estudos de Cultura Contemporânea (ECCO), da Universidade Federal de Mato Grosso (2015), com bolsa CAPES. Graduada em Psicologia pela Universidade Federal de Mato Grosso (2013). Desenvolveu durante a graduação Projeto de Pesquisa pelo Programa Voluntariado de Iniciação Científica (2009-2010) e pelo Programa Institucional de Bolsas de Iniciação Científica (2010-2011), com bolsa CNPq . Realiza estudos sobre os processos de medicalização e farmacologização da existência, capitalização da vida nos mercados de saúde, produção de subjetividades e estudos foucaultianos. Atualmente, é Professora Titular do Curso de Psicologia do UNIVAG - Centro Universitário de Várzea Grande.

${ }^{1}$ HLA são proteínas localizadas em todas as células do corpo humano e, quando duas pessoas possuem HLA compatível, elas são imunologicamente compatíveis. A maioria dos casos de rejeição dos transplantes está relacionada com a incompatibilidade entre as moléculas do HLA do doador e do receptor.

Este artigo de revista Estudos e Pesquisas em Psicologia é licenciado sob uma Licença Creative Commons Atribuição-Não Comercial 3.0 Não Adaptada. 